\title{
Valognes - Rue du Balnéaire
}

$n^{\circ} 3459$

\section{Laurent Paez-Rezende, Gaël Léon et Laurent Vipard}

\section{(2) OpenEdition}

Édition électronique

URL : http://journals.openedition.org/adlfi/16810

ISSN : 2114-0502

Éditeur

Ministère de la culture

Référence électronique

Laurent Paez-Rezende, Gaël Léon et Laurent Vipard, «Valognes - Rue du Balnéaire », ADLFI.

Archéologie de la France - Informations [En ligne], Basse-Normandie, mis en ligne le 26 février 2016, consulté le 03 mai 2019. URL : http://journals.openedition.org/adlfi/16810

Ce document a été généré automatiquement le 3 mai 2019.

(c) Ministère de la Culture et de la Communication, CNRS 


\title{
Valognes - Rue du Balnéaire
}

$n^{\circ} 3459$

\author{
Laurent Paez-Rezende, Gaël Léon et Laurent Vipard
}

Lien Atlas (MCC) :

http://atlas.patrimoines.culture.fr/atlas/trunk/index.php?

ap_theme=DOM_2.01.02\&ap_bbox=-1.514;49.448;-1.437;49.536

1 L'emprise de cette intervention est située sur les marges orientales de la ville actuelle, sur les terrains de l'ancienne commune d'Alleaume, absorbée par Valognes en 1867. Plus précisément, les parcelles sont localisées sur le versant de la rive gauche du Merderet, et présentent une forte déclivité sud-est/nord-ouest.

2 La proximité des terrains par rapport à la bordure occidentale du périmètre estimé de l'agglomération antique d'Alleaume confère à ce diagnostic un enjeu particulier visant, entre autres, la reconnaissance du contexte archéologique à la périphérie de la ville ancienne, sur les versants exposés au nord de la vallée du Merderet. Ainsi, cette intervention a permis de recueillir des informations dans les parcelles distantes d'à peine $300 \mathrm{~m}$ des thermes nord, fouillés entre 1989 et 1992.

3 Malgré la présence d'indices d'une fréquentation antérieure, tels que du mobilier hors contexte et un cercle probablement funéraire, et dont la chronologie reste à préciser, l'empreinte archéologique est principalement constituée par un réseau de fossés antiques à contemporains, fondé sur des orientations nord-ouest/sud-est et perpendiculaires. Cette trame est en léger décalage vis-à-vis des orientations générales nord-sud et estouest repérées au cœur de la ville (rues, ruelles, maçonneries et fossés), sur le plateau ainsi que sur sa bordure immédiate. Toutefois, les mobiliers collectés sur les parcelles AS. 4, 5 et 6 indiquent que les segments les plus anciens ont bien été mis en place durant l'Antiquité et sont, à l'évidence, fondateurs de la trame parcellaire encore active. Le décalage d'orientation avec la trame urbaine viendrait d'une adaptation à la contrainte topographique que constitue le versant de la rive gauche du Merderet et dont le pendage 
devait être certainement plus marqué durant l'Antiquité si l'on occulte l'amplitude de colluvions accumulées au pied du versant.

INDEX

Index géographique : Basse-Normandie, Manche (50), Valognes

Mots-clés : fossé

Index chronologique : Gallo-romain

operation Diagnostic (EV)

\section{AUTEURS}

LAURENT PAEZ-REZENDE

Inrap 